\title{
Forensic neuropsychological assessment: a review of its scope
}

\author{
Antonio de Pádua Serafim ${ }^{1,2}$, Fabiana Saffi ${ }^{1}$, Thais Guerra Barbosa da Silva ${ }^{2}$, Camila Viana de Almeida ${ }^{2}$, \\ Erica Hokama², Daniel Martins de Barrosi, Alvaro Machado Dias3
}

I Forensic Psychiatry and Psychology Unit, Institute and Department of Psychiatry, Medical School, São Paulo University (FMUSP), São Paulo, SP, Brazil.

2 Program of Health Psychology, Methodist University of São Paulo (Umesp), São Bernardo do Campo, SP, Brazil.

${ }^{3}$ Clinical Neuroscience Laboratory, Federal University of São Paulo (Unifesp), São Paulo, SP, Brazil.

Received: 10/28/2014 - Accepted: 3/17/2015

DOl: 10.1590/0101-60830000000049

\begin{abstract}
Background: Issues related to the field of mental health and justice require a multifactorial understanding of the possible causes of such issues. Objective: To conduct an integrative literature review of controlled studies describing forensic neuropsychological assessment. Methods: The articles were compiled and analyzed in two phases: 1) first, we retrieved all papers in PubMed by the keywords "Forensic Neuropsychology" and generated a growth curve for the subject and a cluster-based thematic distribution of publications. 2) We then conducted a curated analysis of all relevant papers indexed in Medline, PubMed and ISI, between 2000 and 2012. Results: The evolution of the field during the last 15 years reveals an unstable growth pattern and three main thematic clusters. In terms of our curated analysis, a total of 390 articles were pre-selected, resulting in the selection of 44 fully-relevant studies, which comprise four main categories: cognitive damage in forensic psychiatric patients; imitation of cognitive damage; civil capacity, penal liability and violence risk; and validation of neuropsychological assessment tools. Discussion: Two aspects appeared as the most relevant in this study: growth in the use of neuropsychological assessment as a diagnostic tool in the forensic context; and the necessity to enhance conformity in assessments.
\end{abstract}

Serafim AP et al. / Arch Clin Psychiatry. 2015;42(2):63-7

Keywords: Neuropsychological assessment, forensic neuropsychology, cognitive damage, memory, mental retardation, forensic psychiatry.

\section{Introduction}

The increase in urban violence, requests for leaves due to disabling diseases, legal procedures for managing bio-psychological hazards from contamination (lead, mercury, carbon monoxide), among other events with psychosocial impact, have increasingly required the participation of psychologists in determining liabilities and compensation for legal damages, within a multidisciplinary-team scope.

The development of systematic methods for evaluation of psychological consequences caused by events of impact and the increased mapping of affective and cognitive processes in social disruptive behaviors has in the last twenty years affected the practice of psychologists who work within the boundaries of the legal system, specifically in regards to neuropsychology, leading to specialization in forensic psychology $y^{1,2}$.

Unlike Clinical Neuropsychology, which determines any dysfunction of cognitive functions, the main aim of forensic neuropsychology is to provide answers to a legal matter: the mapped dysfunction - and the psychological situation in the background, in the broadest meaning - and its effects on a person's ability for understanding and self-determination ${ }^{3,4}$. Also, according to Larrabee $^{5}$, in a synthetic way, the clinic seeks to help the patient, while the goal of forensic assistance is to discover the real facts. The forensic neuropsychological assessment is also distinguished from the clinical field, since the requestor is a third party, and communication of the results takes place among the expert witness and the requestor, and the assessment should be restricted to issues that are developed to respond to the legal matter.

For obvious reasons, the number of studies in clinical neuropsychology is much greater than in forensic ${ }^{6}$, although there have already been some publications from this field in some countries ${ }^{7-11}$. In practice, this means there is a gap in instruments and methodologies that address the previously mentioned issues (liability, psychosocial impact).

Forensic neuropsychology assessment makes its appearance in the expert testimony phase. This is understood here as application of methods and techniques from psychological and neuropsychological research in order to support the lawsuit every time there are questions concerning the psychological "health" of the examined ${ }^{12}$.

It is noteworthy that the procedure of expert testimony should be based on criteria prepared by the legal agent (judge, prosecutor, procurator, delegate, attorney), and it falls to the expert witness to investigate a wide range of mental functionings of the individual involved in a court action of any kind (civil, labor, criminal, etc.), through an exam of his personality and cognitive functions.

For Heilbrun et al. ${ }^{2}$ neuropsychological assessment of forensic character is essential for expert testimony; according to the definition of Lezak et al. ${ }^{13}$, it consists of a complex process, since it requires from the professional not just wide knowledge and mastery in clinical and psychometric psychology, but also strict training in the nervous system (central and autonomic), its pathologies and their consequences.

Authors like Bush ${ }^{11}$, Denney and Sullivan ${ }^{14}$ emphasize that utilization of neuropsychological assessment in forensic context can contribute to the understanding of human behavior, whether transgressive or not, within the scope of biological, psychological, social and cultural instances as modulators of expression of behavior.

The field of forensic neuropsychology is relevant indeed. However, some consideration is needed. For example, Gross ${ }^{15}$ call attention to the widespread use of brain imaging as court evidence. For this, the author points out the so-called "hype" that has been well documented in relation to application of neural imaging to legal matters.

Another issue is forensic neuropsychology related to questions of legal certainty and scientific probability. From a psychological perspective, these legal standards raise questions about reliability and validity, particularly whether tests are predictive of everyday functioning, and in estimating error rates in clinical judgments. Another important aspect is the problem of establishing or estimating premorbid, baseline functioning in the absence of prior testing, and this can often take on great clinical importance in assessing cognition in a courtroom setting. Equally important are assumptions about free will versus determinism in relation to the practice of forensic neuropsychology, which require professional careful attention ${ }^{16-18}$. 
The objective of the present work is to present a review of the literature concerning the use of neuropsychological assessment tools in the forensic setting.

\section{Methods}

The present study is an integrative literature review. The research consisted of integrative review, focused on controlled studies that described the neuropsychological assessment only when applied as part of expert testimony in the forensic field. Given this objective, the definition of descriptors and final selection was made by consensus among researchers.

The selection of articles for this work took place in two phases: in the first, all the digital results from PubMed found through the keyword "Forensic Neuropsychology" were downloaded and we mapped a growth curve of the field and thematic distribution of the publications.

In a second phase, we started with a detailed analysis focused on recent studies. Bibliographical research was completed through Medline, PubMed and ISI, during the 2000 to 2012 period. We used the following descriptors: forensic neuropsychological; forensic neuropsychological assessment. Original articles, case reports and reviews were considered. Inclusion criteria: studies using control group (normal) for comparison with forensic groups. Case Reports, Literature Review and Description of procedures for the forensics field (standards) (Figure 1).

Exclusion criteria: studies that did not describe the relation between neuropsychological assessment and the practice of forensic expert testimony.

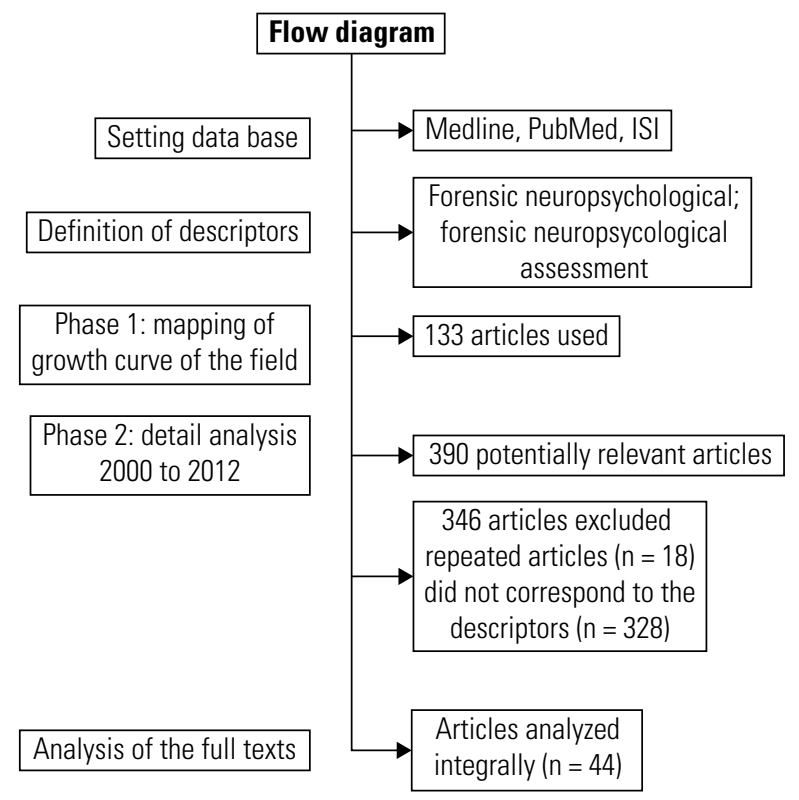

Figure 1. Manuscript selection process.

\section{Results}

The first search (Forensic Neuropsychology in PubMed, every year) retrieved 133 articles, the first one from 1983 and the last one from April 2014 (the month the search was conducted). As revealed by this search, the progression of the field mostly took place in the last 15 years, with no stability by years, in relation to the number of publications. This pattern is typical in fields that are still maturing - which reinforces the perspective that ad-hoc tools are still being refined.

Using the same database and the automated system for verbal pattern recognition recurrence (indexers, title, abstract), in the above-mentioned software, the following image was generated, which clusters the field thematically, and which is organized, throughout its history as expressed in figure 2 .

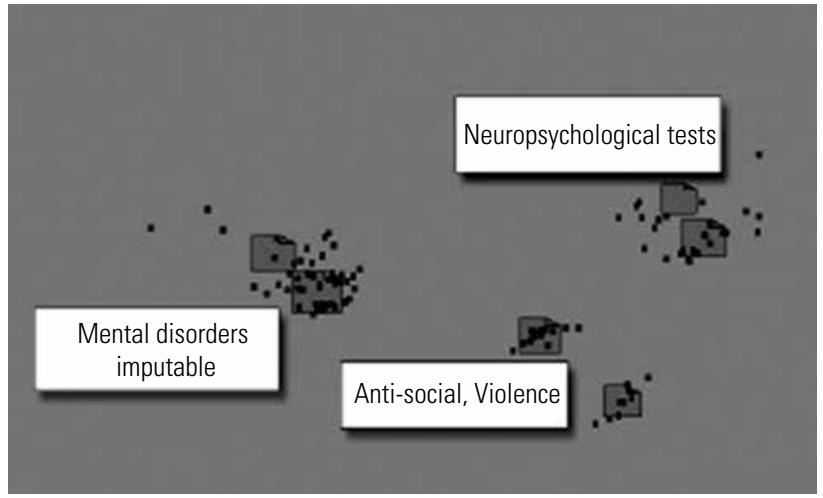

Figure 2. Thematic overview of the field generated through text mining.

As we can see, there are three main areas: discussion of psychiatric conditions capable of determining convictions, development and application of neuropsychological assessment and studies focused on understanding of violence and, related to this, the role of anti-social behavior.

Now undergoing a detailed review and considering the descriptors already mentioned, we pulled a total of 390 articles from the databases searched. Through manual selection, we produced a base with 44 works considered fully relevant to forensic neuropsychology (studies with this as the central topic - as opposed to legal studies or psychiatric studies that use the topic as a support strategy). A careful reading of these articles suggests groupings in four categories (Table 1):

Table 1. Descriptors categories

\begin{tabular}{|l|l|}
\hline Categoria & N \\
\hline $\begin{array}{l}\text { Neuropsychological Assessment for verification of cognitive damage in } \\
\text { forensic psychiatric patients }\end{array}$ & 9 \\
\hline $\begin{array}{l}\text { Neuropsychological Assessment for verification of simulation of } \\
\text { cognitive damage }\end{array}$ & 6 \\
\hline $\begin{array}{l}\text { Neuropsychological Assessment for verification of civil capacity, penal } \\
\text { liability and risk of violence }\end{array}$ & 17 \\
\hline $\begin{array}{l}\text { Descriptions of methods, procedures, standards, validation of } \\
\text { instruments, range and limits of Neuropsychological Assessment in the } \\
\text { forensic field }\end{array}$ & 12 \\
\hline Total & 44 \\
\hline
\end{tabular}

The Neuropsychological Assessment for verification of cognitive damage in forensic psychiatric patients: the core interest in the studies is the verification of cognitive damage in forensic psychiatric patients; they concentrate on psychotic symptoms and are mostly transversal studies.

Neuropsychological Assessment for verification of simulation of cognitive damage: there was a consensus among researchers regarding this descriptor, given the high frequency of claims of psychic damage in legal contexts, whether criminal or civil. Among them, claims of memory loss are especially important.

The Neuropsychological Assessment for verification of civil capacity, penal liability and risk of violence: based on the categories used for organizing this paper, there are a number of prominent studies that investigate the direct relationship between neuropsychological performance, civil capacity, penal liability and risk for violent behavior. This field was responsible for about $38 \%$ of the researched articles.

Finally, in terms of descriptions of methods, procedures, standards, validation of instruments, range and limits of Neuropsychological Assessment in the forensic field: forensic examiners in general agree that their contributions to the judicial process must be based on scientific principles, high ethical values and clinical skills for legal understanding. These are the objectives pursued in this category. 


\section{Discussion}

The results were analyzed according to the four descriptors.

\section{Neuropsychological Assessment for verification of cognitive damage in forensic psychiatric patients}

Nestor et al. ${ }^{19}$, analyzed 26 individuals with mental disorders convicted of homicide, hospitalized in a maximum security forensic hospital, looking at functions such as memory, intelligence, attention, executive functions and academic abilities. The results produced two different subgroups: one defined by higher incidence of psychosis and low level of psychopathy, and another defined by low incidence of psychosis and higher level of psychopathy, each one corresponding to distinct neuropsychological differences in intellectual abilities, learning difficulties and social intelligence. Despite the results, the authors highlight the need for studies with larger samples for better understanding and reliability of neuropsychological measures for this population.

Bentall and Taylor ${ }^{20}$, in a review of studies, investigated the implications of paranoid delusion in the neuropsychological context with forensic repercussions. For these authors, the conditions of paranoia have not been consistently associated with any specific neuropsychological abnormality. However, they highlighted three aspects of paranoid thinking that require better investigation. This would include the paranoia that produces motivations and anomalous perceptive experiences and distortion in reasoning. In a second case, there is association of paranoia with hearing impairment. And finally, there seems to be a strong association between negative paranoia and self-esteem.

Reviewing studies by Naudts and Hodgins ${ }^{21}$ shows that they considered neurobiological correlates and antisocial behavior in schizophrenia. Generally speaking, it was concluded that few studies have been conducted, and that the samples are not significant, which comprises the confirmation of hypotheses.

In analyzing the executive functions of 33 patients with a history of violence, and 49 nonviolent patients, Fullam and Dolan ${ }^{22}$, no significant differences between groups in neuropsychological task performance were found. However, they considered that the lower the IQ, the greater the association with violence. These authors also consider the association between neuropsychological deficits and violence in patients with schizophrenia to be limited and the results inconsistent.

In another study, the histories of violence and neuropsychological aspects of 301 individuals were investigated, from the first report of psychotic outbreak 7 . The results show that $33.9 \%$ of men and $10 \%$ of women had a record of criminal condemnation; $19.9 \%$ of men and $4.6 \%$ of women had been condemned for at least one violent crime. The patients presented the lowest scores on neuropsychological variables (work memory, executive functions and IQ). The authors considered that occasional health service interventions for patients from the first psychotic outbreak can reduce this occurrence, as well as recurrence of violent behavior.

A second branch of studies regarding Neuropsychological Assessment for verification of cognitive damage in forensic psychiatric patients encompasses the consequences of PTSD and patients with brain lesions.

In this area, studies by Rosen and Powel ${ }^{23}$ describe a case report on the use of the Symptoms Validation Test (SVT) to verify memory in post-traumatic patients. For these authors, as the literature states, people with organic brain dysfunction have problems with attention, executive function and social interaction. This procedure can be used as tool in the forensic field. Bastert and Schläfke ${ }^{24}$ assessed 125 patients with organic brain dysfunction with a battery of neuropsychological tests to measure executive functions. The results demonstrated that although these patients presented cognitive performances that are below average, when compared to people without organic dysfunction, the differences were are not as significant as expected. The authors also emphasize that the results suggest that these kinds of patients can benefit from neuropsychological rehabilitation programs.

Examined through neuroimages, the tests and and psychological assessment of 15 patients, the results suggest that these patients, in fact, presented more difficulties in executive capacities. In addition, it is necessary to group these patients by kind of brain lesion, to better define interventional actions ${ }^{25}$.

Bailie et al. ${ }^{26}$, investigated the cognitive ability of 260 patients interned in a forensic hospital. The main results demonstrate that $35.8 \%$ of the sample showed scores below average on a test that measured repetition capacity. Furthermore, $65 \%$ of the participants reported history of delayed development, or less than 12 years of education, or learning difficulties. Half the sample reported at least one neurological risk factor (e.g., history of head trauma with loss of consciousness). However, the neurological risk factors in a certain way do not influence performance on the self-reported test of neurological risks factors. These results corroborate the relevance of neuropsychological services in psychiatric hospitals as a means for intervention ${ }^{26}$.

\section{Neuropsychological Assessment for verification of simulation of cognitive damage}

Authors such as García et al. ${ }^{27}$, Domingo, Gierok et al. ${ }^{28}$, and Burton et al. ${ }^{29}$, considered it essential to have deeper studies on neuropsychological instruments to assess memory, in order to investigate sensitivity for detecting simulation of mnemonic deficits in different forensics contexts.

The authors also emphasize the need for guidelines in future research on the topic, since growth in the forensic field was observed. Scott ${ }^{30}$ emphasizes the need to master concepts, training and memory systems, in addition to the trigger causes of amnesia. The medical history and neuropsychological tests variation is crucial in this process ${ }^{30}$.

In fact, this research area is relevant since, according to Grøndahl et al. ${ }^{31}$, about a third of the defendants in homicide cases claim amnesia (partial or total) during the alleged act. Examining the authenticity of the claimed amnesia is a challenge for forensic experts and therefore, requires development of guidelines for standard proceedings assessment for these claims. This procedure will certainly contribute to more reliable and valid assessment for forensic experts, which will result in fewer contestations of their results in a legal context ${ }^{31}$.

It is understood that the development of studies in this field is necessary when we consider, for example, cases of supposed intellectual disability, as highlighted by Musso et al. ${ }^{32}$, given that in simulated cases for this condition, the tools for assessment of neurocognitive functioning are not consistent for identifying the simulation.

\section{Neuropsychological Assessment for verification of civil capacity, penal liability and risk of violence}

In terms of risk of violence, two articles ${ }^{1,33}$ highlight the relationship between neurocognitive functions and risk of violence, as well as recidivism. Beyond the psychotic symptoms, the studies also investigated the participation of specific brain areas for a variety of cognitive dysfunctions that present themselves as risk variables for violence, such as frontal lobe dysfunction, orbitofrontal/front/front-temporal and/or subcortical regions of the limbic system.

The neuropsychological investigation in the penal/criminal area stands out in quantity when compared to civil capacity or risk evaluation, and presents itself in studies of two specific groups. The first issex offenders ${ }^{34-37}$. The second group involves criminals in a general way, e.g. antisocial and psychopaths $s^{38,39-42}$.

Denney and Wynkoop ${ }^{3}$ and Heilbronner et al. ${ }^{8}$ debate in their works the difference in clinical neuropsychological assessment in the criminal forensic area. These authors write from the perspective that the professional body in the field of neuropsychology has mostly clinical experience, with little experience in criminal matters. 
Regarding studies related to civil matters, the articles describe protocols for assessment of verbal function ${ }^{43}$ and assessment of damage after traumatic brain injury ${ }^{44}$, and presentation of case reports about civil capacity assessment in elderly people ${ }^{45}$.

\section{Descriptions of methods, procedures, standards, validation of instruments, range and limits of Neuropsychological Assessment in the forensic field}

In this context, the neuropsychological exam is an important tool for cognitive function assessment in clinical and forensic situations ${ }^{9,46}$. According to Archer et al. ${ }^{47}$, this is due to methods of investigation that have won "general acceptance" in the field. In this way, the development of methodological strategies, tools, as well as a series of recommendations that can guide procedures for utilization of neuropsychology in the forensic field follows the studies' expectations for this topic $2,6,11,49,50$.

An article by $\mathrm{Hom}^{4}$ calls attention to these observations, emphasizing that the main responsibility of the forensic neuropsychologist is to provide information based on neuropsychological principles that are scientifically validated, relevant to the forensic issue, and not just related to whether the patient has a dysfunction, but if the results of dysfunction have causal relation within the legal issue.

Essig et al. ${ }^{1}$, also within this context of standardization of procedures, addresses the question of quality of communication of documents resulting from the neuropsychological assessment and the understanding of lawyers.

Therefore, we conducted a review of the literature guided by two-phase analysis. Based on mapping the progression of the field of forensic neuropsychology (Phase 1), it can be seen that this area is growing, both in the consolidation of professional practice and in the context of the search. As previously stated, this pattern is typical in fields that are still maturing - which reinforces the perspective that ad-hoc tools are still being refined.

However, in all the articles analyzed there are no doubts about the definition and process of the application, as described below. Forensic neuropsychology is the application of neuropsychological science and methods to the legal system. A forensic neuropsychological examination is performed by a neuropsychologist who is hired as an independent contractor by a third party, such as an attorney, insurance company, or the courts, to make a determination regarding neuropsychological functioning. Forensic neuropsychological evaluations in civil litigation often involve determination of the presence or absence of neurological and/or psychiatric disorders, with causality related to a specific event or injury, documentation of the extent of functional deficits, discussion of limitations of competence or daily functioning, prognosis, medical necessity of treatment and/or disability status. The neuropsychological examination may be used to assist in determining competency to stand trial, issues of responsibility for the crime, or in sentencing/mitigation in criminal litigation.

Given the recognized growth of neuropsychological assessment in the forensic field, mainly in relation to expert testimony, we held the hypothesis that a considerable number of articles dealing with description and standardization of this practice existed when we organized this review. Although we have identified 12 articles in the category "Descriptions of methods, proceedings, standards, validation of instruments, range and limits of Neuropsychological Assessment in forensic field" just two ${ }^{2}$ works discuss standards and conduct of the practice of neuropsychological assessment in order to address legal issues ${ }^{6,48}$.

In our view, this aspect presents itself as essential in regards to neuropsychological assessment interface and the forensic field. Authors like Archer et al. ${ }^{47}$, highlight that even in the U.S., which created the Area of Law and Psychology, linked to the American Psychology Association, responsible for forensic psychology training, there are also cases in which clinical psychologists are often called to testify in court on civilian or criminal cases about questions related to mental health. According to these authors, when this happens, there is frequent risk of contesting, with claims of inappropriate use of techniques and psychological tests.

Therefore, we understand the need for standardization of procedures for investigating cognitive functions, for documentation of production arising from this assessment (report) and for answers to questions prepared by professionals in the judiciary.

Despite the fact that expert psychological testimony has been part of the psychologist's role in Brazil since 1962 through Law 4.119 of August 27 of that year, preparatory courses for the Expert Psychologist are virtually nonexistent. When we refer to training in forensic neuropsychology, this also does not exist. This would suggest the need for changes in the country's schools of psychology, to better organize for this purpose.

We emphasize that this training becomes essential and that it should be considered, when hearing expert psychological and/or neuropsychological testimony, and including 1) training and competence of the expert; 2) knowledge of legal rules; and 3) the proper selection and use of psychological and neuropsychological instruments. In regards to example 3, use of inappropriate techniques and neuropsychological tests that do not meet or answer the courts, are in fact more common than one might expect ${ }^{51}$.

One limitation of this review is the narrowness of its scope, since only forensic neuropsychology studies were considered. However, the objective was precisely this, to assess the specific issues regarding the field.

In conclusion, two aspects are relevant in this review. The first refers to the growth in the use of neuropsychological assessment as a diagnostic resource in the forensic context. The second is related to the need for development of uniformity in the process and resources used in this field, since there is no regulatory procedures and standardization of instruments in the legal system. There are many examples of the interplay between neuropsychology and legal decisions. An example is the increasing life expectancy around the world, and with it major changes in the capacity of the elderly in daily activities; neuropsychological assessment certainly will meet the need to quantify this and many other requests. In a general way, forensic experts agree that their contributions to the legal process must be based on scientific principles, ethical values, combined with clinical and judgment skills.

Therefore, broader research in this area is needed, as well as the establishment of centers for development of forensic neuropsychologists.

\section{Disclosure}

The authors report no conflicts of interest.

\section{References}

1. Sreenivasan S, Kirkish P, Shoptaw S, Welsh RK, Ling W. Neuropsychological and diagnostic differences between recidivistically violent not criminally responsible and mentally ill prisoners. Int J Law Psychiatry. 2000;23(2):161-72.

2. Heilbrun K, Marczyk GR, DeMatteo D, Zilmer EA, Harris J, Jennings T. Principles of forensic mental health assessment: implications for neuropsychological assessment in forensic contexts. Assessment. 2003;10(4):329-43.

3. Denney R, Wynkoop T. Clinical neuropsychology in the criminal forensic setting. J Head Trauma Rehabil. 2008;15:804-28.

4. Hom J. Forensic neuropsychology: are we there yet? Arch Clin Neuropsychol. 2003;18(8):827-45

5. Larrabee GJ. Forensic Neuropsychology: A Scientific Approach. New York: Oxford University Press; 2005.

6. Heilbronner RL. A status report on the practice of forensic neuropsychology. Clin Neuropsychol. 2004;18(2):312-26.

7. Hodgins S, Calem M, Shimel R, Williams A, Harleston D, Morgan C, et al. Criminal offending and distinguishing features of offenders among persons experiencing a first episode of psychosis. Early Interv Psychiatry. 2011;5(1):15-23. 
8. Heilbronner RL, Sweet JJ, Attix DK, Krull KR, Henry GK, Hart RP. Official position of the American Academy of Clinical Neuropsychology on serial neuropsychological assessments: the utility and challenges of repeat test administrations in clinical and forensic contexts. Clin Neuropsychol. 2010;24(8):1267-78.

9. Ruff R. Best practice guidelines for forensic neuropsychological examinations of patients with traumatic brain injury. J Head Trauma Rehabil. 2009;24(2):131-40.

10. Schwarz L, Schrift M, Pliskin N. Forensic neuropsychological evaluations in an academic medical center. J Head Trauma Rehabil. 2009;24(2):100-4.

11. Bush SS. Independent and court-ordered forensic neuropsychological examinations: official statement of the National Academy of Neuropsychology. Arch Clin Neuropsychol. 2005;20(8):997-1007.

12. Bush SS, Lees-Haley PR. Treats to the validity of forensic neuropsychological data: ethical considerations. J Forensic Neuropsychol. 2006;4(3):45-66.

13. Lezak MD, Howieson DB, Loring DW. Neuropsychological Assessment. New York: Oxford University Press; 2004.

14. Denney RL, Sullivan JP. Clinical neuropsychology in the forensic setting. New York: John \& Willey; 2008.

15. Gross C. Between brain and imaging hype. Science. 2013;349:1526.

16. O'Hara EA. How neuroscience might advance the law. Philosophical Transactions of The Royal Society London. 2004;359:1677-84.

17. Melton GB, Petrilia J, Poythress NG, Slobogin C. Psychological evaluations for the courts. A handbook for mental health professionals and lawyers. Second Edition. New York, NY: The Guilford Press; 2007.

18. Gazzaniga MS. Neuroscience in the courtroom. Scientific American. 2011;304:54-9.

19. Nestor PG, Kimble M, Berman I, Haycock J. Psychosis, psychopathy, and homicide: a preliminary neuropsychological inquiry. Am J Psychiatry. 2002;159(1):138-40.

20. Bentall RP, Taylor JL. Psychological processes and paranoia: implications for forensic behavioural science. Behav Sci Law. 2006;24(3):277-94.

21. Naudts K, Hodgins S. Schizophrenia and violence: a search for neurobiological correlates. Curr Opin. Psychiatry. 2006;19(5):533-8.

22. Fullam RS, Dolan MC. Executive function and in-patient violence in forensic patients with schizophrenia. Br J Psychiatry. 2008;193(3):247-53.

23. Rosen GM, Powel JE. Use of a Symptom Validity Test in the forensic assessment of Posttraumatic Stress Disorder. J Anxiety Disord. 2003;17(3):361-7.

24. Bastert E, Schläfke D. Forensic patients with organic brain disorders. World J Biol Psychiatry. 2011;12(Suppl 1):23-7.

25. Bastert E, Schläfke D, Pein A, Kupke F, Fegert JM. Mentally challenged patients in a forensic hospital: a feasibility study concerning the executive functions offorensic patients with organic brain disorder, learning disability, or mental retardation. Int J Law Psychiatry. 2012;35(3):207-12.

26. Bailie JM, King LC, Kinney D, Nitch SR. The relationship between self-reported neuropsychological risk factors and RBANS test performance among forensically committed psychiatric inpatients. Appl Neuropsychol Adult. 2012;19(4):279-86.

27. García Domingo G, Negredo López L, Fernández Guinea S. Evaluating the simulation of memory problems within the legal and forensic fields. Rev Neurol. 2004;38(8):766-74.

28. Gierok SD, Dickson AL, Cole JA. Performance of forensic and non-forensic adult psychiatric inpatients on the Test of Memory Malingering. Arch Clin Neuropsychol. 2005;20(6):755-60.

29. Burton V, Vilar-López R, Puente AE. Measuring effort in neuropsychological evaluations of forensic cases of Spanish speakers. Arch Clin Neuropsychol. 2012;27(3):262-7.

30. Scott CL. Evaluating amnesia for criminal behavior: a guide to remember. Psychiatr Clin North Am. 2012;35(4):797-819.
31. Grøndahl P, Vaerøy H, Dahl AA. A study of amnesia in homicide cases and forensic psychiatric experts' examination of such claims. Int J Law Psychiatry. 2009;32(5):281-7.

32. Musso MW, Barker AA, Jones GN, Roid GH, Gouvier WD. Development and validation of the Stanford Binet-5 rarely missed items-nonverbal index for the detection of malingered mental retardation. Arch Clin Neuropsychol. 2011;26(8):756-67.

33. Klöppel S. Brain morphometry and functional imaging techniques in dementia: methods, findings and relevance in forensic neurology. Curr Opin Neurol. 2009;22(6):612-6.

34. Suchy Y, Whittaker JW, Strassberg DS, Eastvold A. Neurocognitive differences between pedophilic and nonpedophilic child molesters. J Int Neuropsychol Soc 2009;15(2):248-57.

35. Young MH, Justice JV, Edberg P. Sexual offenders in prison psychiatric treatment: a biopsychosocial description. Int J Offender Ther Comp Criminol. 2010;54(1):92-112.

36. Schiffer B, Vonlaufen C. Executive dysfunctions in pedophilic and nonpedophilic child molesters. J Sex Med. 2011;8(7):1975-84.

37. Kruger TH, Schiffer B. Neurocognitive and personality factors in homoand heterosexual pedophiles and controls. J Sex Med. 2011;8(6):1650-9.

38. Dolan M, Millington J, Park I. Personality and neuropsychological function in violent, sexual and arson offenders. Med Sci Law. 2002;42(1):34-43.

39. Morgan AB, Lilienfeld SO. A meta-analytic review of the relation between antisocial behavior and neuropsychological measures of executive function. Clin Psychol Rev. 2000;20(1):113-36.

40. Ardolf BR, Denney RL, Houston CM. Base rates of negative response bias and malingered neurocognitive dysfunction among criminal defendants referred for neuropsychological evaluation. Clin neuropsychol. 2007;21(6):899-916.

41. Greene E, Cahill BS. Effects of neuroimaging evidence on mock juror decision making. Behav Sci Law. 2012;30(3):280-96.

42. Dolan $M$. The neuropsychology of prefrontal function in antisocial personality disordered offenders with varying degrees of psychopathy. Psychol Med. 2012;42(8):1715-25.

43. Fontana P, Dagnino F, Cocito L, Balestrino M. Handwriting as a gauge of cognitive status: a novel forensic tool for posthumous evaluation of testamentary capacity. Neurol Sc. 2008;29(4):257-61.

44. Wortzel HS, Filley CM, Anderson CA, Oster T, Arciniegas DB. Forensic applications of cerebral single photon emission computed tomography in mild traumatic brain injury. J Am Acad Psychiatry Law. 2008;36(3):310-22.

45. Miguel F, Moreira A, Colón M. The donating capacity of the elderly: a case report of vascular dementia. J Forensic Leg Med. 2012;19(7):426-7.

46. Morel KR. Test security in medicolegal cases: proposed guidelines for attorneys utilizing neuropsychology practice. Arch Clin Neuropsychol. 2009;24(7):635-46.

47. Archer RP, Buffington-Vollum JK, Stredny RV, Handel RW. A survey of psychological test use patterns among forensic psychologists. J Pers Assess. 2006;87(1):84-94.

48. Verdejo A, Alcázar-Córcoles MA, Gómez-Jarabo GA, Pérez-García M. Guidelines for the scientific and professional development of forensic neuropsychology. Rev Neurol. 2004;39(1):60-73.

49. Nelson NW, Sweet JJ, Berry DT, Bryant FB, Granacher RP. Response validity in forensic neuropsychology: exploratory factor analytic evidence of distinct cognitive and psychological constructs. J Int Neuropsychol Soc. 2007;13(3):440-9.

50. Wood RL. The scientist-practitioner model: how do advances in clinical and cognitive neuroscience affect neuropsychology in the courtroom? J Head Trauma Rehabil. 2009;24(2):88-99.

51. Essig SM, Mittenberg W, Petersen RS, Strauman S, Cooper JT. Practices in forensic neuropsychology: perspectives of neuropsychologists and trial attorneys. Arch Clin Neuropsychol. 2001;16(3):271-91. 